\title{
The effect of Sc additions on the microstructure and age hardening behaviour of as cast Al-Sc alloys
}

\author{
S. Costa*, H. Puga, J. Barbosa, A.M.P. Pinto \\ CT2M - Centre for Mechanical and Materials Technologies, Universidade do Minho, Azurém 4800-058, Guimarães, Portugal
}

\section{A R T I C L E I N F O}

\section{Article history:}

Received 29 April 2012

Accepted 13 June 2012

Available online 22 June 2012

\section{Keywords:}

Aluminium alloys

Grain refinement

Precipitation strengthening

\begin{abstract}
A B S T R A C T
The grain refinement effect and the ageing behaviour of Al-0.5 wt.\% Sc, Al-0.7 wt.\% Sc, and Al-1 wt.\% Sc alloys are studied on the basis of optic microscopy (OM), scanning electron microscopy (SEM), X-ray diffraction (XRD) observations and hardness measurements. In Al-Sc alloys the higher grain refinement is observed for Sc contents greater than $0.5 \mathrm{wt}$.\% accompanied by a notorious morphology modification, from coarse columnar grains to a fine perfect equiaxed structure. The as cast structures are characterized by a rich supersaturated solid solution in Sc, that promotes a great age hardening response at $250{ }^{\circ} \mathrm{C}$ and $300^{\circ} \mathrm{C}$. The age hardening curves also demonstrate a low overageing kinetics for all the alloys. Although the higher Sc content in solid solution for the alloys with 0.7 and $1 \mathrm{wt} . \% \mathrm{Sc}$, the age hardening response of all the Al-Sc alloys remains similar. The direct age hardening response of the as cast $\mathrm{Al}-0.5 \mathrm{wt} . \% \mathrm{Sc}$ is shown to be greater than the solutionised and age hardened alloy.
\end{abstract}

(c) 2012 Elsevier Ltd. All rights reserved.

\section{Introduction}

Aluminium alloys are widely used in industrial applications, with particular emphasis to transportation industries, owing to the particular combination of low density, high corrosion resistance and high strength to weight ratio. The strength of aluminium alloys is mainly due to age hardening mechanisms. However, in order to fulfil the new requirements of service structural aircraft and automobile components, alloys with higher resistance at high temperatures are needed. One of the most promising approaches to improve the mechanical properties of aluminium alloys is based on the addition of alloying elements either with low solubility or totally insoluble in aluminium. Among the range of possible elements, Scandium is the most effective precipitation hardener element in $\mathrm{Al}$ alloys [1-4]. Heat treatments in the range of $250-350{ }^{\circ} \mathrm{C}$, reported to promote considerably precipitation hardening in $\mathrm{Al}(\mathrm{Sc})$ alloys with Sc content up to $1 \mathrm{wt} . \%[5,6]$. The high response to hardening mechanisms is a consequence of the fine homogeneous dispersion of $\mathrm{Al}_{3} \mathrm{Sc}$ particles, formed during decomposition of the $\alpha \mathrm{Al}$ supersaturated solid solution, which nucleates in aluminium matrix and grain boundaries, thus blocking the dislocations motion [2,7-10]. It has also been reported on a per atom basis, Sc has higher strength effect than $\mathrm{Zr}$ [11]. Thus far, small scandium additions (up to $0.8 \mathrm{wt} . \%$ ) have been reported to greatly improve aluminium alloys properties, including mechanical strength [12-14]. Scandium additions up to $2 \mathrm{wt} . \%$, has been

\footnotetext{
* Corresponding author. Tel.: +351 253510220; fax: +351 253516007.

E-mail address: s.costa@live.com.pt (S. Costa).
}

described to promote an increase in strength of $50 \mathrm{MPa}$ in aluminium in the as cast state and $80 \mathrm{MPa}$ in homogenised state [15]. For wrought aluminium alloys, namely $\mathrm{Al}-\mathrm{Mg}$, low Sc additions (up to 0.35 wt.\%) is reported to increase strength in 100-200 MPa [16]. Concerning to the casting needs, hypereutectic additions of Sc $(0.55 \mathrm{wt} . \%)$ to aluminium alloys induce the formation of fine equiaxed structures (25-50 $\mu \mathrm{m}$ ), acting like a stronger inoculant when compared to the traditional Al-Ti, Al-Ti-B and Al-Ti-C master alloys, which produces coarser grain structures $(150-250 \mu \mathrm{m})$ and have high tendency to induce fading phenomena [15,17-19]. Due the scarcity on the study of the combined effect of Sc addition and optimised heat treatments on aluminium alloys, the main aim of this work is to study the effect of Sc addition on the microstructure of as cast Al-Sc alloys and the ageing hardening response of as cast alloys with and without solution heat treatment.

\section{Material and experimental procedure}

Aluminium alloys containing $0.5,0.7$ and $1 \mathrm{wt} . \%$ Sc were produced using Al-2 wt.\% Sc master alloy and commercially pure Al. The alloys were melted in a graphite crucible using a high frequency induction furnace and poured into a copper mould to obtain $16 \mathrm{~mm}$ internal diameter and $86 \mathrm{~mm}$ long cast samples. The compositions of the studied alloys are given in Table 1. A thermocouple was positioned in the centre of the mould cavity to measure the cooling rate. For the alloys production the Al melt was heated up to $720^{\circ} \mathrm{C} \pm 5$ and the $\mathrm{Al}-2 \mathrm{Sc}$ addition was done. Temperature was kept constant for $30 \mathrm{~min}$ for melt homogenization, which was assumed by the stirring effect caused by the induction coil. 
Table 1

Composition the experimental alloys (wt.\%).

\begin{tabular}{lllllll}
\hline Alloy & $\mathrm{Al}$ & $\mathrm{Sc}$ & $\mathrm{Si}$ & $\mathrm{Fe}$ & $\mathrm{Cu}$ & Other \\
\hline Al-0.5Sc & 99.18 & 0.52 & 0.10 & 0.09 & 0.02 & 0.09 \\
Al-0.7Sc & 99.02 & 0.72 & 0.14 & 0.08 & 0.02 & 0.02 \\
Al-1Sc & 98.31 & 1.20 & 0.33 & 0.06 & 0.03 & 0.07 \\
\hline
\end{tabular}

In order to prevent solid state reactions, the castings, once solidified, were water quenched.

To evaluate the influence of the cooling rate, a portion of the $\mathrm{Al}$ $0.7 \mathrm{Sc}$ alloy was poured directly into water.

In order to study the effect of solution heat treatments, two agehardening treatments were preformed: in one, the Al-0.5Sc alloy was solution treated at $600{ }^{\circ} \mathrm{C}$ for $24 \mathrm{~h}$, water quenched to room temperature and aged, in air, at different temperatures, between 250 and $400{ }^{\circ} \mathrm{C}$ with holding times in the range 0-8192 min. Age hardening treatments of the as cast alloys (Al-0.5Sc, Al-0.7Sc and $\mathrm{Al}-1 \mathrm{Sc}$ ), were also carried out at $300^{\circ} \mathrm{C}$, without previous solution treatment.

Samples were polished down to $0.025 \mu \mathrm{m}$ with non-crystallized colloidal silica and anodized with Barker's reagent and observed under polarised light in order to reveal the microstructure. Samples casted into water, were only etched with Keller's reagent, due to their complex shape. The microstructure morphology and grain size were checked by OM, using a Leica DM $2500 \mathrm{M}$. The grain roundness was evaluated according Eq. (1), where $A$ is the grain area and $P$ is the grain perimeter. A value of 1 indicates a perfect circle and as the value approaches to 0 points out to an increasingly elongated polygon, like columnar grain structures.

$R_{n}=\frac{4 \pi A}{P^{2}}$

In order to get detailed information on the microstructure and chemical composition, the samples were characterized on NanoSEM-FEI Nova 200 FEG/SEM scanning electron microscope equipped with energy dispersive spectrometer (EDS) EDAX-Pegasus X4 M operating at accelerated voltage of $15 \mathrm{kV}$. Phases analysis was carried out by XRD using a Bruker D8 DISCOVER diffractometer equipped with $\alpha \mathrm{Cu}$ Ka radiation source.

Vickers hardness measurements were performed on as cast and heat treated samples. Eight measurements were made for each condition, using $30 \mathrm{kgf}$ load and $20 \mathrm{~s}$ dwell.

\section{Results and discussion}

\subsection{Microstructure of as cast alloys}

Fig. 1a shows the typical grain structure of high purity aluminium without any addition of grain refiner. As expected, this structure is characterized by large columnar grains, with a dendritic substructure. This type of structure has been described to reduce workability, yield strength and ductility of aluminium alloys [19]. As cast microstructures of Al-Sc alloys with 0.5, 0.7 and $1 \mathrm{wt} . \%$ Sc contents are presented in Fig. 1b-d, respectively. For the Al$0.5 \mathrm{wt} . \%$ Sc alloy shown in Fig. 1b, there is a slight modification of grain structure, resulting the coexisting of smaller columnar and equiaxed grains smaller than those of cpAl (Fig. 1a). In fact results presented on Fig. 2 shows a decrease on the grain size and suggest a trend partial equiaxed structure although Fig. 1b still reveals that a dendritic substructure allied to columnar grain still persists. These results suggest that, despite the slight morphology modification and grain refinement, Sc content is still not enough to produce a perfect equiaxed structure. These results are supported by the Al-rich phase diagram [19], that shows that for Sc contents less than $0.55 \mathrm{wt} . \%$, the first forming phase is $\alpha \mathrm{Al}$, resulting in a coarse columnar structure. This phenomenon is more pronounced in this alloy due to the high solidification rate (measured $\sim 300 \mathrm{~K} /$ $\mathrm{s})$, since the eutectic composition shifts to right, so the Sc content necessary for grain refinement gets higher.

When Sc content is increased to $0.7 \mathrm{wt} . \%$ there is no evidence of columnar grains, as seen in Fig. 1c. The same behaviour is observed in the Al-1 wt.\% Sc alloy (Fig. 1d). In these cases the columnar structure is replaced by a fine equiaxed structure throughout the (a)

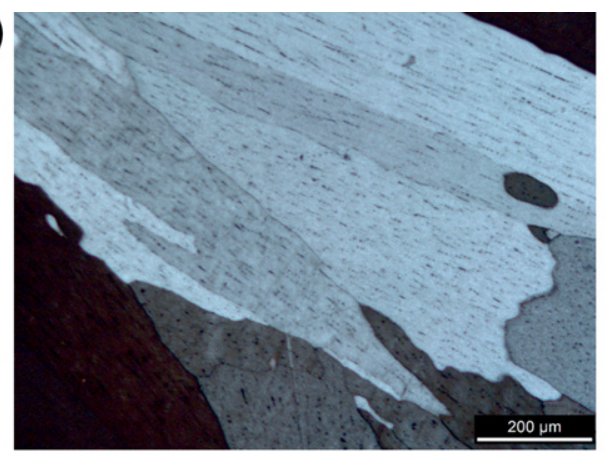

(b)

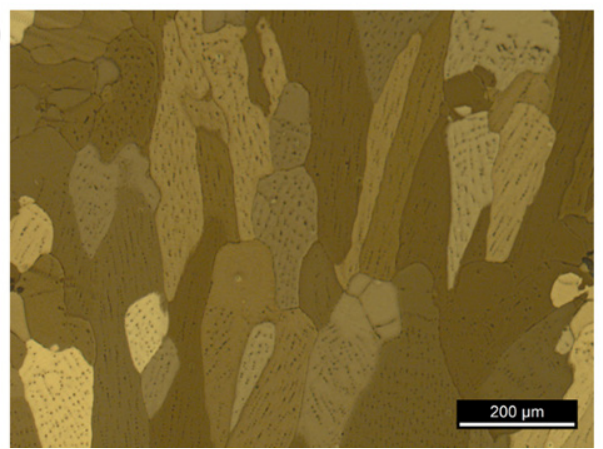

(c)

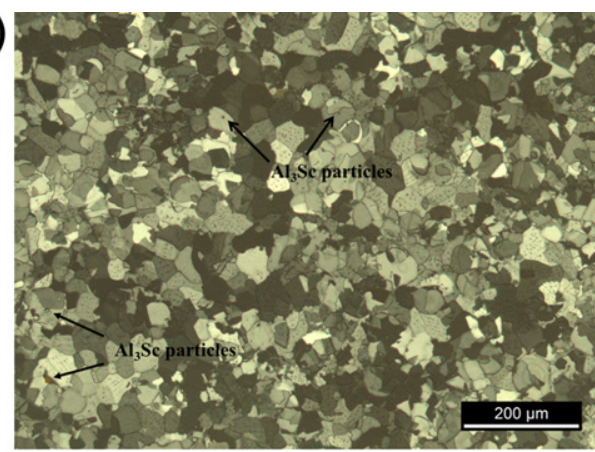

(d)

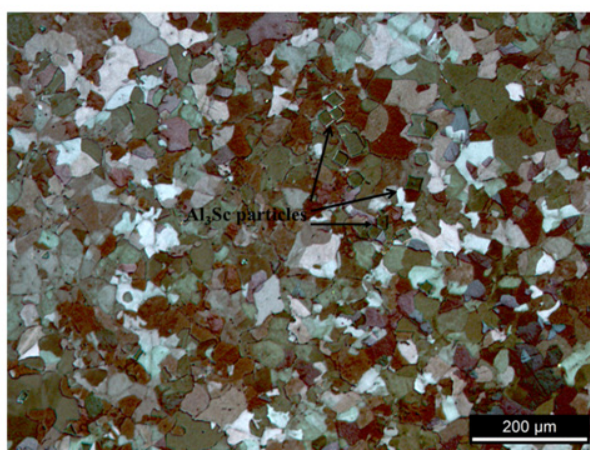

Fig. 1. Low magnification optical micrographs of as cast: (a) $\mathrm{Al} \mathrm{cp}$; (b) $\mathrm{Al}-0.5 \mathrm{Sc}$; (c) $\mathrm{Al}-0.7 \mathrm{Sc}$ and (d) $\mathrm{Al}-1 \mathrm{Sc}$. 


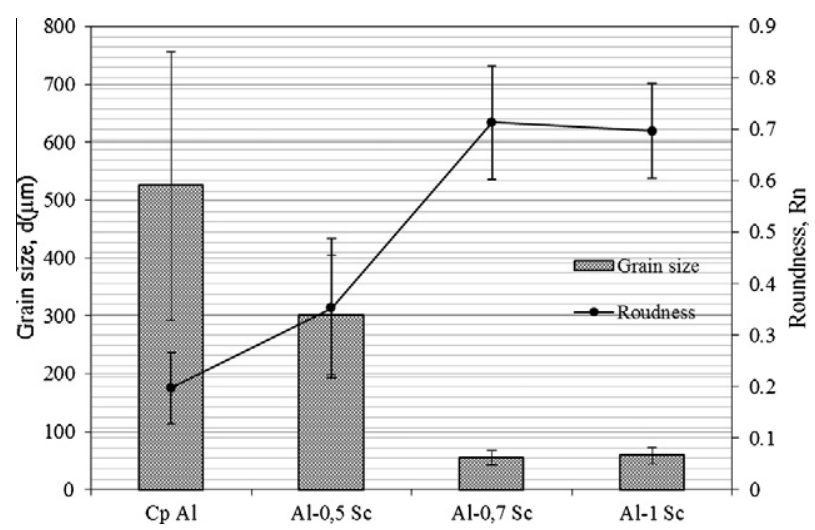

Fig. 2. Average grain size and roundness of Al-Sc alloys as a function of the Sc content.

sample, which is of extremely importance to the performance of a cast component. In fact, it is well known that a fine and equiaxed grain microstructure has numerous benefits in cast alloys, improving the mechanical properties, distribution of second phase precipitates, reducing shrinkage porosity and improve the achievement of uniform anodized surfaces [20,21]. Fig. 2, shows the evolution of the average grain size and morphology with Sc content in AlSc alloys. Significant decrease on the grain size and increase on the roundness factor for increasing Sc contents are clearly observed suggesting the evolution from a coarse columnar to a perfect fine equiaxed grain structure. According to these results, an increase in Sc content above $0.7 \mathrm{wt} . \%$ does not bring any benefit in grain refining. These outcomes prove the great efficiency of Sc as a grain refiner, when in excess of the eutectic composition. The formation of a perfect equiaxed structure is due to the precipitation of the $\mathrm{L1}_{2}$ $\mathrm{Al}_{3} \mathrm{Sc}$ phase, which is the first forming phase from the melt in hypereutectic alloys. Owing the similarities between crystal structures of the FCC $\alpha \mathrm{Al}$ matrix and $\mathrm{Al}_{3} \mathrm{Sc}$ phase, and the small mismatch $(\sim 1.6 \%)$ [15] between these phases, the $\mathrm{Al}_{3} \mathrm{Sc}$ particles act like potent nucleation sites for $\alpha \mathrm{Al}$ grains $[15,22,23]$. For the refined structures, Fig. $1 \mathrm{c}$ and d, the total absence of a dendritic substructure within the equiaxed grains can be observed. These results support the remarks reported in previous studies $[15,18,22]$.

In those alloys with higher Sc content ( $\mathrm{Al}-0.7 \mathrm{Sc}$ and $\mathrm{Al}-1 \mathrm{Sc})$ a significant amount of cuboid particles can also be seen on the microstructure. Particles morphology and composition (66.92 wt.\% Al and $33.41 \mathrm{wt} . \% \mathrm{Sc}$ ), obtained by EDS suggest that these are $\mathrm{Al}_{3} \mathrm{Sc}$ dispersoids. The heterogeneous distribution, the size and morphology of those particles indicate that probably, for the alloys with higher Sc content, the melting conditions did not allow the complete dissolution of the $\mathrm{Al}-2 \mathrm{Sc}$ master alloy and, therefore, some $\mathrm{Al}_{3} \mathrm{Sc}$ did not dissolved and remains in the melt. As it can be observed in Fig. 1b, the $\mathrm{Al}_{3} \mathrm{Sc}$ cubic particles are not detected in Al-0.5Sc. The XRD result of the as cast structure of this alloy, presented in Fig. 3, suggests the total absence of the $\mathrm{Al}_{3} \mathrm{Sc}$ phase, since only $\alpha \mathrm{Al}$ phase peaks are present. XRD results also show a preferential orientation of the columnar grain in the Al-0.5Sc alloy, consequence of the nucleation on the mould wall and post growth into the centre of the casting. On the opposite, for the Al-0.7Sc alloy the XRD analysis confirms a multiple orientated structure characterized by the presence of several $\alpha$ Al peaks with lower intensity, typical of an equiaxed grain structure.

Table 2 shows the Sc content in the $\alpha$ Al solid solution for the alloys in as cast condition. For the $\mathrm{Al}-0.5 \mathrm{Sc}$ alloy, Sc retained in solid solution is $\sim 0.5 \mathrm{wt} . \%$. This value indicates the effectiveness of the copper mould cooling rate in the formation of a supersaturated solid solution. Increasing Sc content to $0.7 \mathrm{wt}$ \% promotes an increase

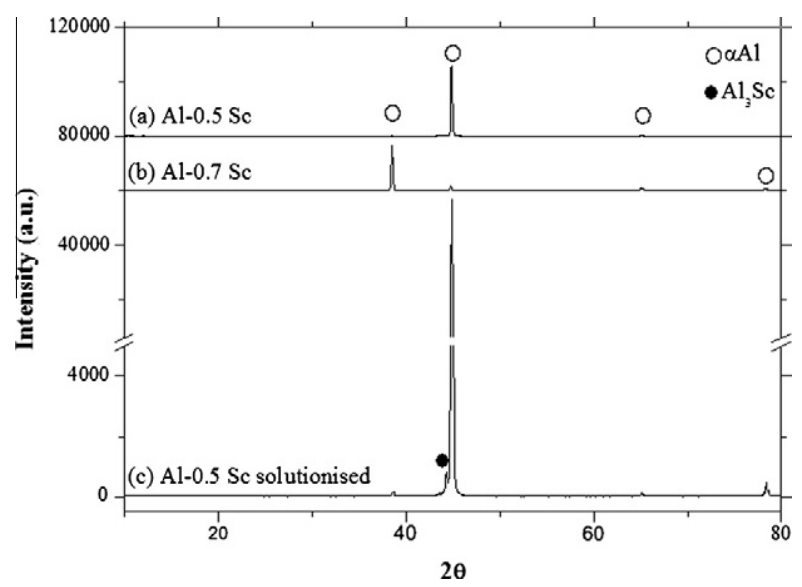

Fig. 3. XRD results for the as cast (a) Al-0.5Sc, (b) Al-0.7Sc alloys and (c) solutionised Al-0.5Sc alloy.

Table 2

Composition of the $\alpha \mathrm{Al}$ solid solution of $\mathrm{Al}-0.5 \mathrm{Sc}, \mathrm{Al}-0.7 \mathrm{Sc}$ and $\mathrm{Al}-1 \mathrm{Sc}$ cast alloys, obtained by EDS (wt.\%).

\begin{tabular}{lll}
\hline Alloy & Al & Sc \\
\hline Al-0.5Sc & $99.49 \pm 0.05$ & $0.51 \pm 0.05$ \\
Al-0.7Sc & $99.35 \pm 0.1$ & $0.65 \pm 0.1$ \\
Al-1Sc & $99.34 \pm 0.07$ & $0.66 \pm 0.07$ \\
Al-0.7Sc (poured into water) & $99.27 \pm 0.08$ & $0.73 \pm 0.08$ \\
\hline
\end{tabular}

of Sc content on the aluminium matrix but for higher contents no enrichment of the solid solution was detected, suggesting that the supersaturated limit of the solid solution for these casting conditions was achieved. According to Toporova LS et al. [23], in order to retain up to $1 \mathrm{wt} . \%$ Sc it is necessary to achieve a cooling rate higher of than $10^{3} \mathrm{~K} / \mathrm{s}$.

Aiming to evaluate the effect of cooling rate on the microstructure and solid solution composition, a little portion of the Al-0.7Sc melted alloy was dropped directly into water and the result is presented in Fig. 4. A perfect equiaxed structure and a decrease on the average grain size ( $36 \pm 9 \mu \mathrm{m})$ are observed, compared to the same alloy poured in copper mould (Fig. 1c). EDS results (Table 2 ) reveals an increase on the Sc content in solid solution. According with Lohar et al. study [24], the increase of the cooling rate promotes deterioration on the Sc refining efficiency, as the number of

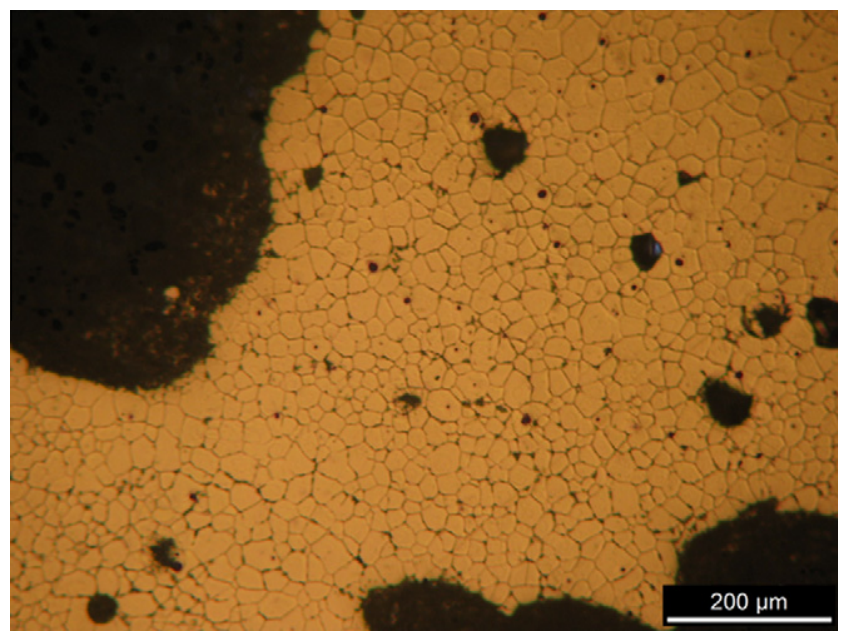

Fig. 4. Low magnification optical micrograph of Al-0.7Sc poured into water 
primary $\mathrm{Al}_{3} \mathrm{Sc}$ particles decreases due to the retention of Sc in solid solution. However, Norman et al. [25] stated that the refining efficiency of Sc remains unaffected with the cooling rate variation, which supports the results of this study. These results display the efficiency of the cooling rate, not only in improving the microstructure but also in enriching the aluminium solid solution, which is supposed to increase the age hardening response of the alloy.

\subsection{Heat treatments}

\subsubsection{Solution heat treatment}

Despite the high supersaturation degree of the as cast solid solution for the three alloys, SEM (Fig. 5a) and EDS (Table 3) analyses of the Al-0.5Sc as cast structure revealed the presence of precipitates containing scandium and iron (marked as $\mathrm{Z3}$ ). The $\mathrm{Al}_{3} \mathrm{Fe}$ precipitation was already expected, since Fe is an inevitable impurity in aluminium alloys. However, according to Davydov et al. [7], who reported a non-reactive behaviour of $\mathrm{Al}_{3} \mathrm{Fe}$ and $\mathrm{Sc}$ when iron content is lower than $0.8 \mathrm{wt} . \%$, the association of scandium with

\section{(a)}

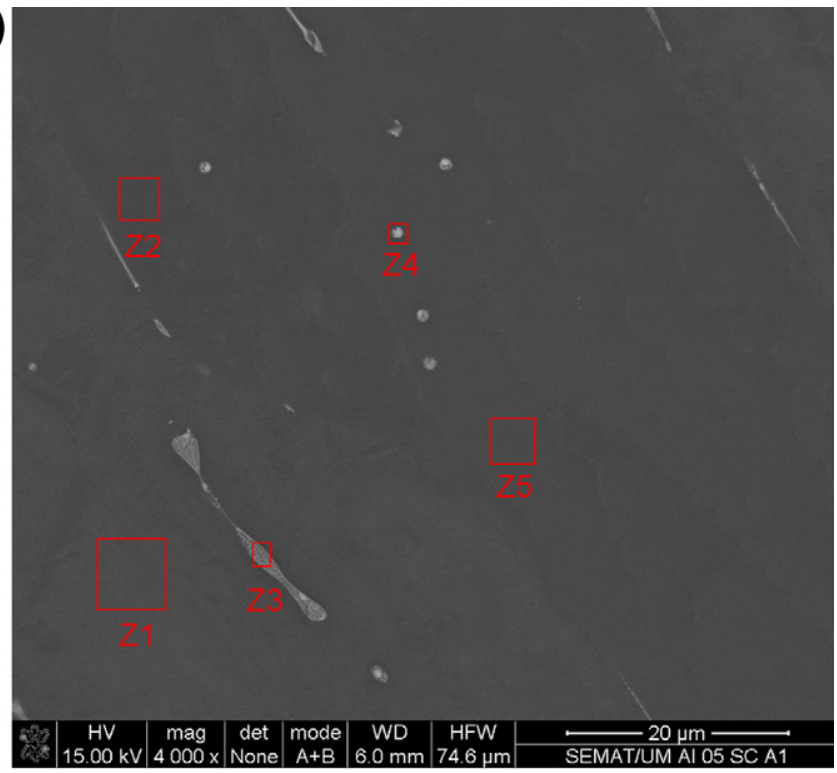

(b)

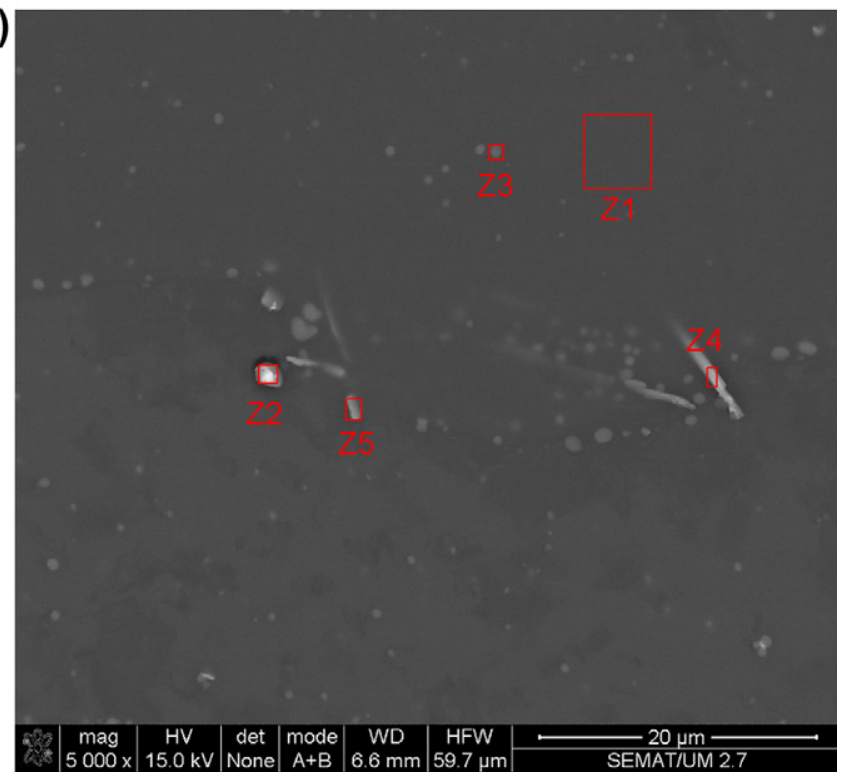

Fig. 5. SEM micrographs of Al-0.5Sc alloy: (a) as cast and (b) solid solution heat treated.
Table 3

Composition of as cast Al-0.5Sc alloy, obtained by EDS (wt.\%).

\begin{tabular}{lllrl}
\hline & $\mathrm{Al}$ & $\mathrm{Sc}$ & $\mathrm{Fe}$ & $\mathrm{Si}$ \\
\hline $\mathrm{Z1}, \mathrm{Z2}$ and Z5 & $99.49 \pm 0.05$ & $0.51 \pm 0.05$ & - & - \\
$\mathrm{Z3}$ & 90.51 & 1.04 & 7.93 & 0.52 \\
$\mathrm{Z4}$ & 88.74 & - & 11.26 & - \\
\hline
\end{tabular}

Table 4

Composition of solubilised Al-0.5Sc alloy, obtained by EDS (wt.\%).

\begin{tabular}{lllll}
\hline & Al & Sc & Fe & Cu \\
\hline Z1 & 99.59 & 0.41 & - & - \\
Z2 & 68.74 & - & 14.25 & 17.01 \\
Z3 & 90.73 & 9.27 & - & - \\
Z4 & 76.05 & - & 18.28 & 5.67 \\
Z5 & 89.23 & - & 10.77 & - \\
\hline
\end{tabular}

these intermetallics was not expected. In order to promote the dissolution of these precipitates and increasing the supersaturation level of the solid solution, the alloy was submitted to a solid solution heat treatment. Fig. 5b and Table 4, show SEM and EDS results for the alloy after the heat treatment. The scandium content in the solid solution (marked as Z1) decreases after solutionizing. This is due to the decomposition of the aluminium solid solution and consequent precipitation of $\mathrm{Al}_{3} \mathrm{Sc}$ during treatment. XRD results for this alloy (Fig. 3), before and after solubilisation heat treatment, confirm the formation of $\mathrm{Al}_{3} \mathrm{Sc}$ particles.

\subsection{Age hardening}

\subsubsection{Age hardening behaviour of as cast and solutionised alloys}

The hardness variation with ageing time in the temperature range $250-400{ }^{\circ} \mathrm{C}$ for the $\mathrm{Al}-0.5 \mathrm{Sc}$ alloy, after solid solution treatment, is shown in Fig. 6 . The curves reveal an excellent ageing response for this alloy. Maximum hardening is reached at $300^{\circ} \mathrm{C} /$ 2048 min. Previous studies of Al alloys with Sc contents between 0.2 and $0.5 \mathrm{wt} . \%$ and heat treated below $350{ }^{\circ} \mathrm{C}$, prove that this great increase in hardness is due to the formation of a homogeneous dispersion of $\mathrm{Al}_{3} \mathrm{Sc}$ coherent nano-sized particles (4-10 nm) [26]. A decrease in hardness is observed after the maximum ageing peak. Which is reported to be a consequence of the loss of coherency $(\sim 40 \mathrm{~nm})$ due to coarsening of $\mathrm{Al}_{3} \mathrm{Sc}$ particles with ageing time [27], that promotes the growth and interparticle spacing of the $\mathrm{Al}_{3} \mathrm{Sc}$ particles [28]. The lower hardness values are achieved for the $400{ }^{\circ} \mathrm{C}$ condition. According to Marquis and Seidman [26], these lower

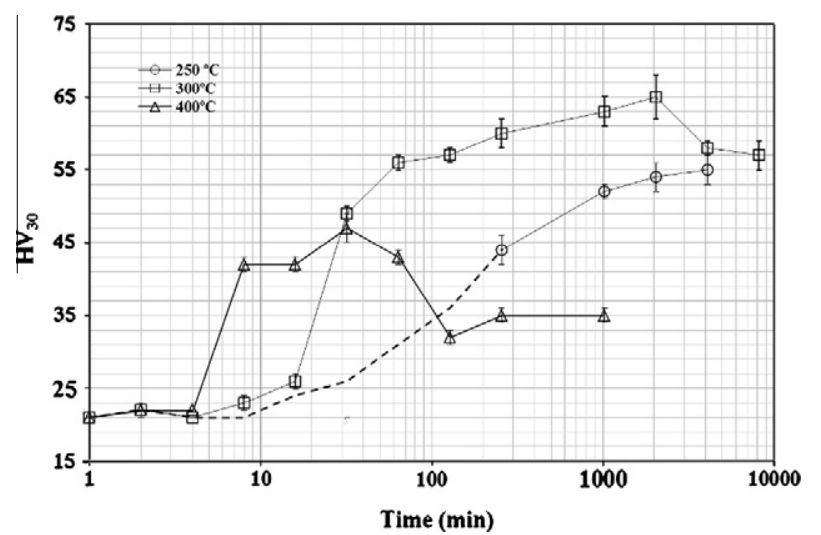

Fig. 6. Age hardening evolution of solubilised $\mathrm{Al}-0.5 \mathrm{Sc}$ alloy at $250^{\circ} \mathrm{C}, 300^{\circ} \mathrm{C}$ and $400^{\circ} \mathrm{C}$. 


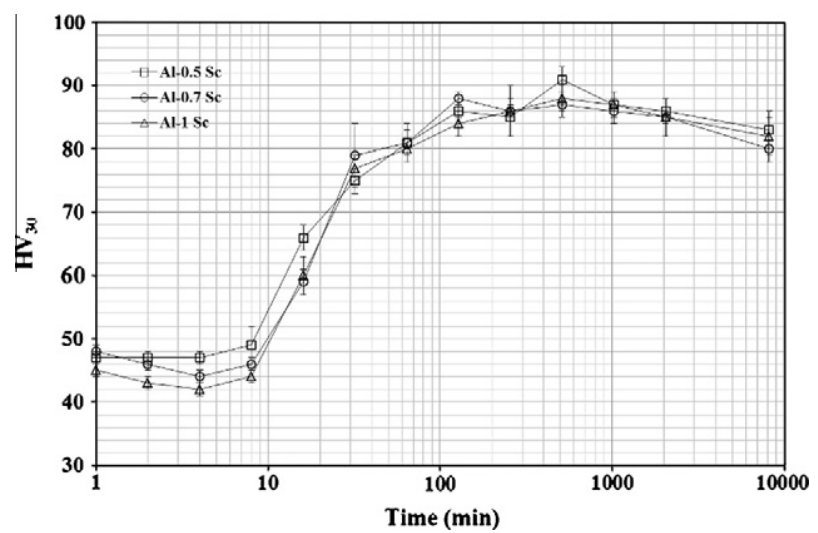

Fig. 7. Effect of Sc content on the age hardening response of as cast Al-Sc alloys at $300{ }^{\circ} \mathrm{C}$.

values are consequence of the high heat treatment temperature which promotes heterogeneous nucleation of the $\mathrm{Al}_{3} \mathrm{Sc}$ precipitates, resulting on a lower volume fraction of higher dimension particles. The effect of temperature in the transition from the coherent to incoherent state is well explained when $250^{\circ} \mathrm{C}$ and $400{ }^{\circ} \mathrm{C}$ ageing curves are compared. Early overageing is observed for the $400^{\circ} \mathrm{C}$, indicating loss of coherency around $64 \mathrm{~min}$. On the other hand, for $250{ }^{\circ} \mathrm{C}$, ageing peak hardness was not reached. From ageing curves observation, it is also verified the low ageing kinetics, consequence of the low diffusivity of Sc in aluminium.

\subsubsection{Age hardening behaviour of as cast alloys}

According to the presented ageing results, the most suitable ageing temperature is $300^{\circ} \mathrm{C}$. This remark is sustained by previous studies, even for $\mathrm{Al}(\mathrm{Sc})$ alloys with different Sc content $[14,29,30]$. Therefore, ageing treatments in as cast $\mathrm{Al}-0.5 \mathrm{Sc}, \mathrm{Al}-0.7 \mathrm{Sc}$ and $\mathrm{Al}-$ 1Sc alloys, were performed at this temperature. Fig. 7 shows the hardness evolution with ageing time for the three alloys. Despite the slight difference of Sc content in solid solution between Al$0.5 \mathrm{Sc}$ and the other alloys, the age hardening response remains similar. Theoretically, during decomposition of richer solid solutions a higher density of $\mathrm{Al}_{3} \mathrm{Sc}$ precipitates is formed, generating higher age hardening responses [26]. Unlike what one might have expected, $\mathrm{Al}-0.7 \mathrm{Sc}$ and $\mathrm{Al}-1 \mathrm{Sc}$ alloys do not show higher ageing response. However, as presented on Section 3.1, the alloys with higher Sc content are characterized by the presence of primary $\mathrm{Al}_{3} \mathrm{Sc}$ particles, consequently the Sc retained in solid solution diffuses preferentially into them, promoting their growth and inhibiting

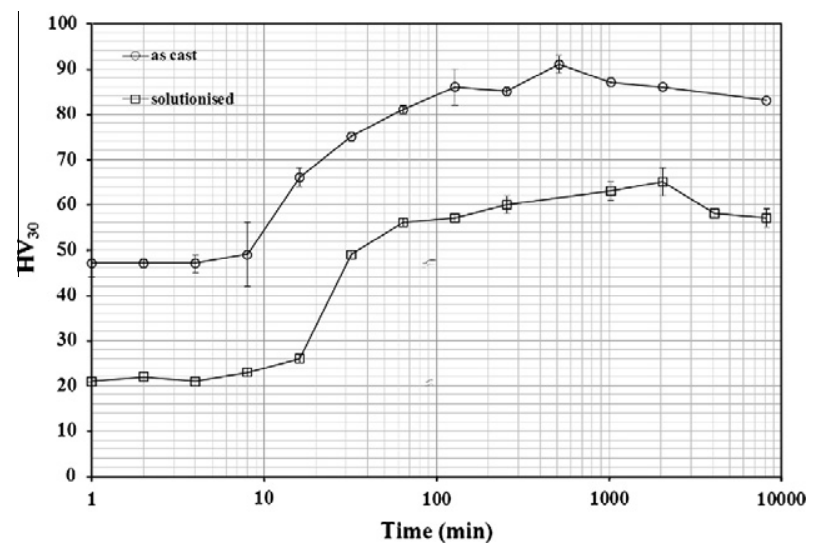

Fig. 8. Evolution of the age hardening of as cast and solubilised $\mathrm{Al}-0.5 \mathrm{Sc}$ alloy at $300^{\circ} \mathrm{C}$. the nucleation in the surroundings, thus decreasing the alloys ageing response [24].

A remarkable fact is revealed when the ageing hardness behaviour of as cast $\mathrm{Al}-0.5 \mathrm{Sc}$ is compared to the ageing hardness behaviour of the as cast and solution treated $\mathrm{Al}-0.5 \mathrm{Sc}$, both aged at $300{ }^{\circ} \mathrm{C}$ (Fig. 8). The hardness values are significantly higher for the aged alloy in the as cast condition and the ageing kinetics is considerably higher. The behaviour of the as cast alloy is a consequence of the higher vacancies density, which contributes for a higher diffusion rate, and the superior Sc content in solid solution, promoting a finer strengthener dispersion of $\mathrm{Al}_{3} \mathrm{Sc}$ particles. One important feature observed in Fig. 8 is the high temperature stability of these alloys, since hardness values keep almost constant during long ageing times, supporting the application of $\mathrm{Al}(\mathrm{Sc})$ alloys in high temperature structures.

\section{Conclusions}

The effect of Sc content and age hardening treatment on the microstructures and ageing behaviour of $\mathrm{Al}-\mathrm{Sc}$ were studied.

Regarding the scandium addition effect it is shown that:

- The scandium grain refinement effect is observed for contents of at least $0.7 \mathrm{wt} . \%$.

- Increasing the Sc content from 0.7 to $1 \mathrm{wt}$ \% does not influence the grain refinement efficiency.

- The presence of coarse primary $\mathrm{Al}_{3} \mathrm{Sc}$ particles increase with the increasing in scandium content, deteriorating the alloys ageing response.

Concerning to heat treatments, the following main conclusions can be drawn from this work:

- The age hardening behaviour of Al-Sc alloys is independent upon the Sc content in the alloy in the range $0.5-1 \%$, but its directly dependent on the supersaturation degree of the solid solution;

- Ageing of as cast alloys, without previous solid solution treatment, not only increase the maximum hardening, but also precipitation kinetics.

\section{References}

[1] Tolley A, Radmilovic V, Dahmen U. Segregation in $\mathrm{Al} 3(\mathrm{Sc}, \mathrm{Zr}$ ) precipitates in $\mathrm{Al}-$ Sc-Zr alloys. Scripta Mater 2005;52:621-5.

[2] Dalen ME, Dunand DC, Seidman DN. Effects of Ti additions on the nanostructure and creep properties of precipitation-strengthened $\mathrm{Al}-\mathrm{Sc}$ alloys. Acta Mater 2005;53:4225-35.

[3] Dalen ME, Gyger T, Dunand DC, Seidman DN. Effects of Yb and Zr microalloying additions on the microstructure and mechanical properties of dilute Al-Sc alloys. Acta Mater 2011:59:7615-26.

[4] Monachon C, Krug ME, Seidman DN, Dunand DC. Chemistry and structure of core/double-shell nanoscale precipitates in Al-6.5 Li-0.07 Sc-0.02 Yb (at.\%). Acta Mater 2011;59:3398-409.

[5] Parker BA, Zhou ZF, Nolle P. The effect of small additions of scandium on the properties of aluminum-alloys. J Mater Sci 1995;30:452-8.

[6] Kaiser MS, Datta S, Roychowdhury A, Banerjee MK. Effect of scandium on the microstructure and ageing behaviour of cast $\mathrm{Al}-6 \mathrm{Mg}$ alloy. Mater Charact 2008;59:1661-6.

[7] Davydov VG, Rostava TD, Zakharov VV, Filatov Yu A, Yelagin VI. Scientific principles of making an alloying addition of scandium to aluminium alloys. Mater Sci Eng A 2000;280:30-6.

[8] Rajinikanth V, Jindal V, Akkimardi VG, Ghosh M, Venkateswarlu K. Transmission electron microscopy studies on the effect of strain on $\mathrm{Al}$ and Al-1\% Sc alloy. Scripta Mater 2007;57:425-8.

[9] Zakharov VV, Rostova TD. Effect of scandium, transition metals, and admixtures on strengthening of aluminum alloys due to decomposition of the solid solution. Metal Sci Heat Treat 2007;49:435-42.

[10] Stock HR, Köhler B, Bomas H, Zoch HW. Characteristics of aluminiumscandium alloy thin sheets obtained by physical vapour deposition. Mater Des 2010;31:576-81 
352

S. Costa et al./Materials and Design 42 (2012) 347-352

[11] Knipling KE, Seidman DN, Dunand DC. Ambient-and high-temperature mechanical properties of isochronally aged $\mathrm{Al}-0.06 \mathrm{Sc}, \mathrm{Al}-0.06 \mathrm{Zr}$ and $\mathrm{Al}-$ 0.06Sc-0.06Zr (at.\%) alloys. Act Mater 2011;59:943-54.

[12] Lee WS, Chen TH, Lin CF, Chen MS. Impact deformation behaviour and dislocation substructure of Al-Sc alloy. J Alloy Comp 2010;493:580-9.

[13] Lee WS, Chen TH. Mechanical and microstructural response of aluminiumscandium (Al-Sc) alloy as function of strain rate and temperature. Mater Chem Phys 2009;113:734-45.

[14] Seidman DN, Marquis EA, Dunand DC. Precipitation strengthening at ambient and elevated temperatures of heat-treatable $\mathrm{Al}(\mathrm{Sc})$ alloys. Acts Mater 2002;50:4021-35.

[15] Venkateswarlu K, Pathak LC, Ray AK, Dos G, Verna PK, Kumar A, et al. Microstructure, tensile strength and wear behaviour of Al-Sc alloy. Mater Sci Eng A 2004;383:374-80.

[16] Filatov YA, Yelagin VI, Zakharov VV. New Al-Mg-Sc alloys. Mater Sci Eng A 2000;280:97-101.

[17] Lohar AK, Mondale B, Rafaja D, Klemm V, Panigrahi SC. Microstructural investigations on as-cast and annealed $\mathrm{Al}-\mathrm{Sc}$ and $\mathrm{Al}-\mathrm{Sc}-\mathrm{Zr}$ alloys. Mater Charact 2009;60:1387-94.

[18] Zakharov VV. Effect of scandium on the structure and properties of aluminum alloys. Metal Sci Heat Treat 2003;45:246-53.

[19] Hyde KB, Norman AF, Prangnell PB. The effect of cooling rate on the morphology of primary $\mathrm{Al}_{3} \mathrm{Se}$ intermetallic particles in $\mathrm{Al}-\mathrm{Sc}$ alloys. Acts Mater 2001;49:1327-37.

[20] Easton M, StJohn D. Grain refinement of aluminum alloys: Part I. The nucleant and salute paradigms - a review of the literature. Metal Mater Trans A 1999;30:1613-23.
[21] Zhang Yijie, Ma Naiheng, Ye Hongzhan, Li Songehun, Wang H. Effect of Fe on grain refinement of commercial purity aluminum. Mater Bes 2006;27:794-8.

[22] Norman AF, Hyde K, Costello F, Thompson S, Berley S, Prangnell PB. Examination of the effect of Sc on 2000 and 7000 series aluminium alloy castings: for improvements in fusion welding. Mater Sci Eng A 2003;354:188-98.

[23] Toporova LS, Eskin DG, Kharakterova ML, Dobatkina TV. Advanced aluminium alloys containing scandium structure and properties. Taylor \& Francis; 1998.

[24] Lohar AK, Mondal BN, Panigrahi SC. Influence of cooling rate on the microstructure and ageing behavior of as-cast Al-Sc-Zr alloy. J Mater Process Tech 2010;210:2135-41.

[25] Norman AF, Prangnell PB, McEwen RS. The solidification behaviour of dilute aluminium-scandium alloys. Act Mater 1998;46:5715-32.

[26] Marquis EA, Seidman DN. Nanoscale structural evolution of $\mathrm{Al}_{3} \mathrm{Sc}$ precipitates in $\mathrm{Al}(\mathrm{Sc})$ alloys. Anta Mater 2001;49:1909-19.

[27] Watanabe $\mathrm{C}$, Kondo T, Monzen R. Coarsening of $\mathrm{Al}_{3} \mathrm{Sc}$ precipitates in an $\mathrm{Al}-0.28$ wt pct Sc alloy. Metall Mater Trans A 2004;35A:3003-8.

[28] Iwamura S, Mira Y. Loss in coherency and coarsening behavior of $\mathrm{Al}_{3} \mathrm{Sc}$ precipitates. Act Mater 2004;52:591-600.

[29] Marquis EA, Seidman DN, Dunant DC. Effect of Mg addition on the creep and yield behavior of an Al-Sc alloy. Acts Mater 2003;51:4751-60.

[30] Royset J, Rum N, Bettella D, Rocco A, Jia Z, Solberg JK, et al. On the addition of precipitation- and work-hardening in an Al-Sc alloy. Mater Sci Eng A 2008;483-484:175-8. 